\title{
Effects of serotonin transporter gene polymorphism on mood during the period before the competition in Japanese ballet dancers
}

\author{
Kanaka Yatabe ${ }^{1 *}$, Toshio Kumai ${ }^{2}$, Hiroto Fujiya ${ }^{1}$, Naoko Yui ${ }^{1}$, Satomi Kasuya ${ }^{3}$, Yuka Murofushi ${ }^{1}$, Keisuke Tateishi ${ }^{1}$, Fumiko Terawaki ${ }^{1}$, \\ Hajime Kobayashi $^{4}$, Aya Uchino ${ }^{4}$, Takaaki Kudo ${ }^{4}$, Mahiro Ohno ${ }^{4}$, Hisao Miyano ${ }^{5}$, Tadasu Oyama ${ }^{6}$ and Haruki Musha ${ }^{1}$ \\ ${ }^{1}$ Department of Sports Medicine, St. Marianna University School of Medicine, Japan \\ ${ }^{2}$ Department of Pharmacogenomics, St. Marianna University Graduate School of Medicine, Japan \\ ${ }^{3}$ Showa University of Music, Japan \\ ${ }^{4}$ Department of Sports Medicine, St. Marianna University Graduate School of Medicine, Japan \\ ${ }^{5}$ Chiba University, Japan \\ ${ }^{6}$ Formerly Nihon University, Japan
}

\begin{abstract}
We investigated whether serotonin transporter gene linked polymorphic region (5-HTTLPR) can predict mood state in Japanese ballet dancers, when they are placed under psychological pressure. Participants were 25 elite student ballet (Elite) dancers with future potential and 19 pro-ballet (Pro) dancers. We administered two psychological questionnaires (STAI: State-Trait Anxiety Inventory; BRUMS: Brunel Mood Scale) to the participants on a typical day and on one of stressful days. The frequency of the 5-HTTLPR genotype in the dancers was as follows: s/s, 64.7\%; s/1, 35.3\%; 1/1, 0\%. There was only significant difference in STAI scores on before-competition between s/s and s/1 genotypes. In this study, the Trait-Anxiety scores of Elite dancers were significantly higher than those of the Pro dancers $(p<0.028)$. The main effects were significant of genotypes in the BRUMS scores $(P<0.035)$ and of Pro/Elite groups $(P<0.002)$; the 5 -HTTLPR has played a certain role in the background of state-trait anxiety, and the psychological test scores were strongly influenced by occupational factors. We can predict the status of BRUMS before the competition by examining the Trait-Anxiety in Elite. Dance level (Elite versus Pro) appears to have far more robust effects on dancer mental status than does 5-HTTLPR genotype.
\end{abstract}

\section{Introduction}

The emotions that we experience on a daily basis are influenced by social factors such as interaction, as well as stimulation from the internal and external environments. Feeling nervous is a common emotional outcome, particularly in competitive sports scenarios such as tournaments and other non-practice scenarios where outcomes are at stake $[1,2]$. State of mind does have an impact on sporting performance. Recently, it has been reported that programmed mental training has positive effects on sport performance $[3,4]$. To optimize the effect of the training, it is important to diagnose and predict what kind of psychological conditions players may experience, and how such conditions might impact performance.

Serotonin, also called 5-hydroxytryptamine $(5-\mathrm{HT})$, is a neurotransmitter widely related to emotional and cognitive processing [5]. A lack of serotonin in the brain is thought to cause depression [6-8]. The 5-HT transporter (5-HTT) is expressed on the presynaptic membrane of serotonergic neurons, and is associated with reuptake of serotonin from the synapses between neurons. It has been shown that the transcription of SLC6A4 (which encodes 5-HTT) can be influenced by genetic polymorphism at the 5-HTT gene linked polymorphic region (5-HTTLPR) [5,9]. The 5-HTTLPR genotype is a repeat polymorphism at the promoter of the SLC6A4 gene, whose alleles include 14 repeats (short) and 16 repeats (long). A short allele is linked with reduced transcriptional activity of the SLC6A4 gene compared with a long allele, which is thought to enhance anxiety. Recently, many investigations have revealed relationships between the 5-HTTLPR genotype and emotional disorders [7,9-11]. Japanese psychological research has examined the connections between this genetic polymorphism and higher brain functions involved in emotion regulation $[12,13]$. The s/s genotype has been frequently observed in Asian populations, including those of Japan and South Korea [13-15]. However, several studies have reported that there is no significant effect of the 5-HTTLPR genotype on neuroticism or other personality traits [16-19]. Thus, the possible association between the 5-HTTLPR genotype and anxiety has remained a controversial topic, although use of different methods for assessing anxiety may account for some of the differences across studies. It is possible that the 5-HTTLPR genotype may have a unique influence on individual performance in Japanese individuals [20]. However, studies of such an effect of the 5-HTTLPR genotype have yet to examine sporting endeavors in a Japanese context.

In the ballet field, the experience level as a dancer may influence a large effect on mental conditions as well as genetic polymorphism. It was expected that modern dancers would experience greater negative

Correspondence to: Kanaka Yatabe, Departmtent of Sports Medicine, St. Marianna University School of Medicine, 2-16-1, Sugao, Miyamae-ku, Kawasaki, Japan, 216-8511, Japan, E-mail: kanaka@marianna-u.ac.jp

Key words: 5-HTTLPR, anxiety, stress

Received: November 01, 2016; Accepted: November 14, 2016; Published: November 18, 2016 
or unpleasant emotion, including the performance anxiety, prior to competition before an audience than prior to final rehearsal [21,22]. Professional dancers can control their psychological conditions, because they have experienced a lot of stress for a living, such as anxiety, occupational stress, perfectionism, and aspiration in the theatrical art unlike student dancers [21-24]. Our past study indicates that Elite ballet dancers with future potential moods were rather stronger in negative feelings on cast decisions or rehearsal day than on before the competition [25], that professionalism as a dancer makes significant differences in the intensity of various mood states [26].

In this observational study, we investigated the effects of the 5-HTTLPR genotype and the occupational factor on various emotions in Japanese ballet dancers under stressful performance conditions.

\section{Materials and methods}

The purpose is to investigate the association between polymorphism in serotonin transporter gene and state-trait anxiety, and to explore the possibility of 5-HTTLPR being used as an objective predictor of mental state in Japanese ballet dancers under the stress conditions. Especially, in order to see if we could predict the psychological condition before the competition using Trait-Anxiety scores instead of 5-HTTLPR genotype, we analyzed the relation between 5-HTTLPR and TraitAnxiety on the typical day, and BRUMS scores in dancers finally.

\section{Participants}

Participants were 25 elite student ballet dancers with future potential (mean age $=18.6$ years, $s=0.6$; Elite) and 19 pro-ballet dancers for their lives (mean age $=29.8$ years, $s=7.2$; Pro), including 4 males and 40 females (total $n=44$ dancers). We administered psychological questionnaires to participants on a typical day, on cast decisions day, on a rehearsal day, and on a day before competition. This investigation has been performed once every two weeks to one month, over the course of a year. The 5-HTTLPR genotypes of 34 females were determined and relationships between genotype and emotional variables were examined.

\section{Ethical statement}

The study was approved by the Ethics Committee of the St. Marianna University School of Medicine and was registered with the UMIN Clinical Trials Registry. The study was described to all participants, who provided their informed consent.

\section{Psychological assessment}

The State-Trait Anxiety Inventory (STAI) and the Brunel Mood Scale (BRUMS) were administered to our sample of Elite and Pro dancers. The STAI is a well-known 40-item self-report questionnaire that measures transient (state) and enduring (trait or stable individual differences in proneness) levels of anxiety [27]. We used the Japanese version of the STAI (STAI-Form JYZ) [28]. Each item on the STAIForm JYZ is rated on a dichotomous subscale, present $(\mathrm{P})$ or absent (A). The STAI was administered according to the standard 20 items questionnaire instructions. The BRUMS is a 24 -item inventory that assesses various emotional or mood states [29]. Dancers were asked to indicate "How are you feeling right now?", and respond to the items on a scale from 0 (not at all) to 4 (extremely), representing various feelings such as Vigour, Tension, Depression, Confusion, Anger, and Fatigue. We used the Preliminary Japanese Version of the BRUMS, a 42-item version, after getting permission from the authors [30,31].

\section{5-HTTLPR genotyping}

DNA samples were taken from the oral mucosa membrane of dancers. DNA was extracted from the buccal epithelium with a swab ( $\gamma$-correct swab R; Eiken Kagaku, Japan), using the QIAamp DNA Micro kit (Qiagen, CA, US). The 5-HTTLPR genotype of each dancer was assessed by polymerase chain reaction (PCR), and cross-checked via at least two primer sets. The genotypes of 13 of 18 Elite dancers, and 15 of 16 Pro dancers, were confirmed by both $1 F / 1 R$ and $2 F / 2 R$ primer sets (Table 1). Because the 5-HTTLPR genotypes of the other dancers were not successfully assessed via $1 F / 1 \mathrm{R}$ and $2 \mathrm{~F} / 2 \mathrm{R}$ primer sets, we used an additional four primer sets to confirm the genotypes (Table 1). PCR amplification was carried out in a $20 \mu \mathrm{L}$ solution consisting of the reaction mixture with 5-10 ng of genomic DNA, 20 or 60 pmol of primers, $0.1 \mathrm{nmol}$ of deoxyribonucleotides (dGTP/7-deazadGTP $=1$, Biolabs, New England, UK), 0.4 U of Q5 ${ }^{\oplus}$ High-Fidelity DNA Polymerase, and $4 \mu \mathrm{L}$ of Q5 High GC Enhancer (Biolabs, New England, UK), using a programmable thermal cycler for 45 cycles (MiniCyclerTM; MJ Research, Inc., MA, US). PCR conditions were as follows: Denaturation at $98^{\circ} \mathrm{C}$ for $10 \mathrm{sec}$, annealing at $58^{\circ} \mathrm{C}$ for $30 \mathrm{sec}$, and extension at $72^{\circ} \mathrm{C}$ for $30 \mathrm{sec}$. The reaction products were electrophoresed through $2 \%$ agarose gel (Agarose LO3, Takara, Japan) with ethidium bromide, and visualized by ultraviolet illumination.

\section{Statistical analysis}

We used MANOVA and two-way ANOVA with repeated measures. Follow-up univariate ANOVAs were used when significant main effects were found, followed by the Bonferroni method. Genotype associations were examined with single regression analysis. The between-group comparison for the Trait-anxiety subscales was conducted using a $t$-test. Pearson correlation coefficients $(r)$ between BRUMS scores and Trait-Anxiety scores on each condition were calculated. Statistical analyses were performed using SPSS ver. 21.0 for computing descriptive statistics. A $p$ value less than 0.05 was considered statistically significant.

\section{Results}

\section{5-HTTLPR genotype frequencies}

To investigate the relationship between 5-HTTLPR genotypes and the various emotional characteristics assessed via the STAI and BRUMS, we first analyzed 5-HTTLPR genotypes of the 34 dancers who underwent genetic analysis. As shown in Table 2, the frequencies of 5-HTTLPR genotypes in the 34 dancers were as follows: s/s, 22 dancers (64.7\%); s/l, 12 dancers (35.3\%); 1/l, none (0\%). 11 Elite (61.1\%) and 11 Pro dancers $(68.8 \%)$ had the s/s allele, whereas 7 Elite $(38.9 \%)$ and

Table 1. Primer sequences for detecting 5-HTTLPR genotype.

\begin{tabular}{|c|c|}
\hline Primer name & Primer sequence (5' to $\mathbf{3}$ ') \\
\hline $1 \mathrm{~F}$ & TGAATGCCAGCACCTAACCC \\
\hline $1 \mathrm{R}$ & TTCTGGTGCCACCTAGACGC \\
\hline $2 \mathrm{~F}$ & TCCTCCGCTTTGGCGCCTCTTCC \\
\hline $2 \mathrm{R}$ & TGGGGGTTGCAGGGGAGATCCTG \\
\hline $3 \mathrm{~F}$ & GGCGTTGCCGCTCTGAATGC \\
\hline $3 \mathrm{R}$ & GAGGGACTGAGCTGGACAACCAC \\
\hline $4 \mathrm{~F}$ & ATGCCAGCACCTAACCCCTAATGT \\
\hline $4 \mathrm{R}$ & GGACCGCAAGGTGGGCGGGA \\
\hline $5 \mathrm{~F}$ & CTTGTTGGGGATTCTCCCGCCTG \\
\hline $5 \mathrm{R}$ & CTGGACAACCACGGGCAAGCGAG \\
\hline $6 \mathrm{~F}$ & CTGTGTTCATCTGAAAGGAGGAGGC \\
\hline $6 \mathrm{R}$ & TACTTGGAGGAACTGACCCCTGAAA \\
\hline
\end{tabular}


5 Pro $(31.3 \%)$ dancers had the s/l allele. There was no difference in the distribution of 5-HTTLPR genotypes between Elite and Pro dancers.

\section{Relationship between the STAI and 5-HTTLPR genotypes}

We next surveyed the Trait-Anxiety of dancers using the STAI on typical and before-competition days. Trait-Anxiety indicates a relatively stable condition of anxiety proneness. As shown in Table 3, Trait-Anxiety total scores were significantly higher for Elite dancers than for Pro dancers, but State-Anxiety were not on both of days. However, total scores of Trait-Anxiety were significantly different among 4 groups (5-HTTLPR within occupational reasons) on the before-Competition.

A two-way ANOVA (5-HTTLPR $\times$ Elite/Pro) for Trait-Anxiety on the typical day and on the before-Competition showed that there was a main effect of Elite/Pro $(P<0.030 ; P<0.003)$, but no significant main effect of the 5-HTTLPR genotype $(P=0.826 ; P=0.594)$. Similarly, there

Table 2. Frequencies of 5-HTTLPR genotypes.

\begin{tabular}{|c|c|c|c|c|c|c|}
\hline \multirow{2}{*}{$\begin{array}{l}\text { 5-HTTLPR } \\
\text { genotype }\end{array}$} & \multicolumn{2}{|c|}{ Elite $(n=18)$} & \multicolumn{2}{|c|}{$\operatorname{Pro}(n=16)$} & \multicolumn{2}{|c|}{ All $(n=34)$} \\
\hline & $n$ & $\%$ & $n$ & $\%$ & $n$ & $\%$ \\
\hline $\mathrm{s} / \mathrm{s}$ & 11 & 61.1 & 11 & 68.8 & 22 & 64.7 \\
\hline $\mathrm{s} / 1$ & 7 & 38.9 & 5 & 31.3 & 12 & 35.3 \\
\hline $1 / 1$ & 0 & 0.0 & 0 & 0.0 & 0 & 0.0 \\
\hline
\end{tabular}

Table 3. State-Trait Anxiety scores.

\begin{tabular}{|c|c|c|c|c|c|c|}
\hline & $\begin{array}{l}\text { Elite/ } \\
\text { Pro }\end{array}$ & $\begin{array}{l}\text { 5-HTTLPR } \\
\text { genotype }\end{array}$ & Typical day & Total & $\begin{array}{l}\text { Before } \\
\text { Compe. }\end{array}$ & Total \\
\hline \multirow{4}{*}{ Trait-A } & \multirow{2}{*}{ Elite } & $\mathrm{s} / \mathrm{s}$ & $50.30(10.85)$ & \multirow{2}{*}{$\begin{array}{c}51.38 \\
(9.26)^{*}\end{array}$} & $51.38(9.22) \dagger$ & \multirow{2}{*}{$\begin{array}{c}53.77 \\
(9.62)^{* *}\end{array}$} \\
\hline & & $\mathrm{s} / 1$ & 53.17 (6.24) & & $57.60(9.94) \dagger$ & \\
\hline & \multirow{2}{*}{ Pro } & $\mathrm{s} / \mathrm{s}$ & $43.82(11.06)$ & \multirow{2}{*}{$\begin{array}{c}43.44 \\
(10.05)\end{array}$} & $43.09(9.84) \dagger$ & \multirow{2}{*}{$\begin{array}{l}42.38 \\
(8.86)\end{array}$} \\
\hline & & $\mathrm{s} / 1$ & $42.60(8.44)$ & & $40.80(6.90) \dagger$ & \\
\hline \multirow{4}{*}{ State-A } & \multirow{2}{*}{ Elite } & $\mathrm{s} / \mathrm{s}$ & $47.40(10.22)$ & \multirow{2}{*}{$\begin{array}{l}46.93 \\
(9.65)\end{array}$} & $44.50(8.80)$ & \multirow{2}{*}{$\begin{array}{l}45.62 \\
(7.84)\end{array}$} \\
\hline & & $\mathrm{s} / 1$ & 45.75 (9.36) & & $47.40(6.50)$ & \\
\hline & \multirow{2}{*}{ Pro } & $\mathrm{s} / \mathrm{s}$ & $46.36(13.40)$ & \multirow{2}{*}{$\begin{array}{c}44.94 \\
(11.29)\end{array}$} & $49.45(9.61)$ & \multirow{2}{*}{$\begin{array}{c}46.56 \\
(10.49)\end{array}$} \\
\hline & & $\mathrm{s} / 1$ & $41.80(3.35)$ & & $40.20(10.43)$ & \\
\hline
\end{tabular}

Note.

Elite vs. Pro dancers $(t): * P<0.028, * * P<0.004$

4 group (5-HTTLPR $\times$ Elite/Pro) $(F): \uparrow P<0.017$.

Table 4. Present/Absence scores of Trait-Anxiety on the typical day. was no significant interaction between 5-HTTLPR genotype and Elite/ Pro status $(P=0.586 ; P=0.253)$. Taken together, these findings suggest that Elite/Pro status influences the Trait-anxiety, with no discernable effect of 5-HTTLPR genotype.

We further divided the Trait-Anxiety scores into present $(\mathrm{P})$ and absent (A) subscales on typical day in accordance with the STAIForm JYZ (Table 4). The 5-HTTLPR genotype had no significant effect on both subscales $(P=0.346 ; P=0.097)$. However, Elite dancers were significantly higher than Pro dancers on subscale A $(P<0.015)$, suggesting that the difference of total scores between two groups observed here is due to this subscale. Elite dancers appear to experience more stress than Pro dancers in unconsciously experience more stress.

\section{Relationship between BRUMS scores and 5-HTTLPR genotypes}

To explore the association between 5-HTTLPR genotypes and emotional state, we administered the BRUMS on four occasions: A typical day, cast decision day, rehearsal day, and before the competition day. Through 4 test days, in the BRUMS scores significant were the main effects of 5-HTTLPR $(P<0.035)$ and of Pro/Elite $(P<0.002)$ groups, and Fatigue scale tended to be the main effects in both factors $(P<0.044$; $P<0.063$ ) (Figure 1). To clarify how BRUMS scores change through 4 test days in each subjects, we further investigated time-dependent changes in various feeling individually. These observations suggest that various emotions in Pro dancers would more hardly change in a time-dependent manner compared with those in Elite. Although Pro dancers performed calmly, their emotions could not be detected by a subjective feeling evaluation.

Figure 1 summarizes BRUMS scores on the four test days. Detailed results were as follows:

Vigour: There was no significant difference across the four test days. Vigour scores had a wide dispersion, and conspicuous differences or time-dependent changes were not observed.

Tension: Tension scores showed no significant differences for 5-HTTLPR and Pro/Elite. But this scores for Pro dancers tended to be significantly lower than those for Elite dancers on the typical day $(P=0.061)$. However, most of the dancers calmed down as time went on, such that there was no difference between Elite and Pro dancers.

Depression and anger: On the typical day, Depression and Anger scores for Pro dancers were significantly lower than those for Elite dancers $(P<0.004 ; P<0.002$, respectively). Anger scores were also lower

\begin{tabular}{|c|c|c|c|c|c|c|c|c|}
\hline \multirow[t]{2}{*}{ Elite/Pro } & \multirow[t]{2}{*}{ 5-HTTLPR genotype } & & \multicolumn{3}{|c|}{ Trait-Anxiety scores on the typical day } & \multicolumn{3}{|c|}{ State-Anxiety scores on the typical day } \\
\hline & & & $\mathbf{P}$ & $\mathbf{A}$ & Total & $\mathbf{P}$ & $\mathbf{A}$ & Total \\
\hline \multirow[t]{2}{*}{ Elite } & $\mathrm{s} / \mathrm{s}$ & & $24.80(5.59)$ & $25.50(5.44)$ & $50.30(10.85)$ & $21.30(6.80)$ & $26.10(4.33)$ & $47.40(10.22)$ \\
\hline & $\mathrm{s} / 1$ & & $25.83(1.94)$ & $27.33(4.41)$ & $53.17(6.24)$ & $18.50(3.32)$ & $27.25(7.63)$ & $45.75(9.36)$ \\
\hline \multirow[t]{2}{*}{ Pro } & $\mathrm{s} / \mathrm{s}$ & & $22.45(5.50)$ & $21.36(6.15)$ & $43.82(11.06)$ & $17.45(6.17)$ & $28.91(8.49)$ & $46.36(13.40)$ \\
\hline & $\mathrm{s} / 1$ & & $21.40(4.16)$ & $21.20(4.32)$ & $42.60(8.44)$ & $13.60(1.14)$ & $28.20(3.83)$ & $41.80(3.35)$ \\
\hline \multirow[t]{3}{*}{$P$ value } & Elite $v s$. Pro & $(t)$ & 0.079 & $0.014 *$ & $0.027^{*}$ & 0.051 & 0.339 & 0.611 \\
\hline & 5-HTTLPR s/s $v s . \mathrm{s} / 1$ & $(t)$ & 0.896 & 0.579 & 0.711 & 0.066 & 0.937 & 0.335 \\
\hline & 5-HTTLPR $\times$ Elite/Pro & $(F)$ & 0.346 & 0.097 & 0.166 & 0.117 & 0.799 & 0.818 \\
\hline
\end{tabular}

Note.

$P$, present anxiety-subscale; $A$, absent anxiety-subscale.

$(t)$; Statistical analysis was performed by using $t$-test, ${ }^{*} P<0.05$.

$(F)$; Statistical analysis was performed by using ANOVA. 
Vigour

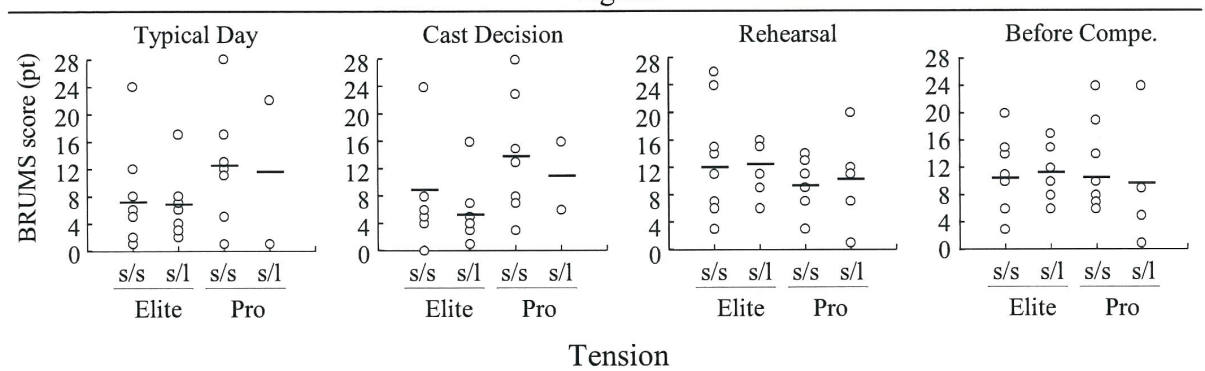

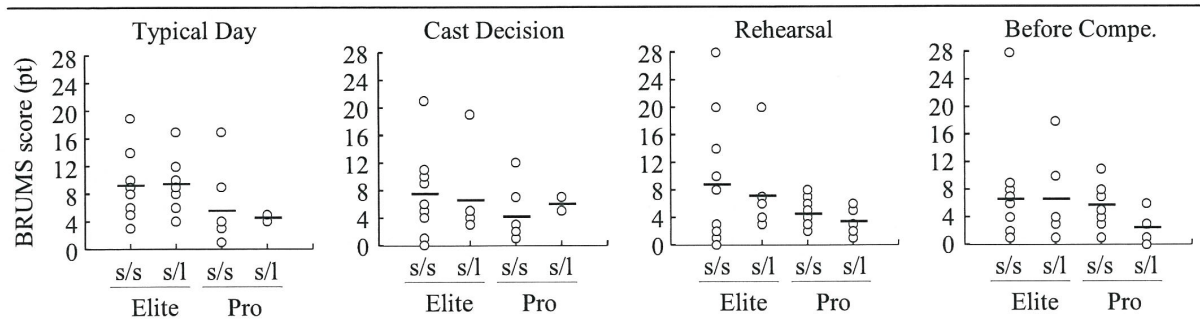

Depression

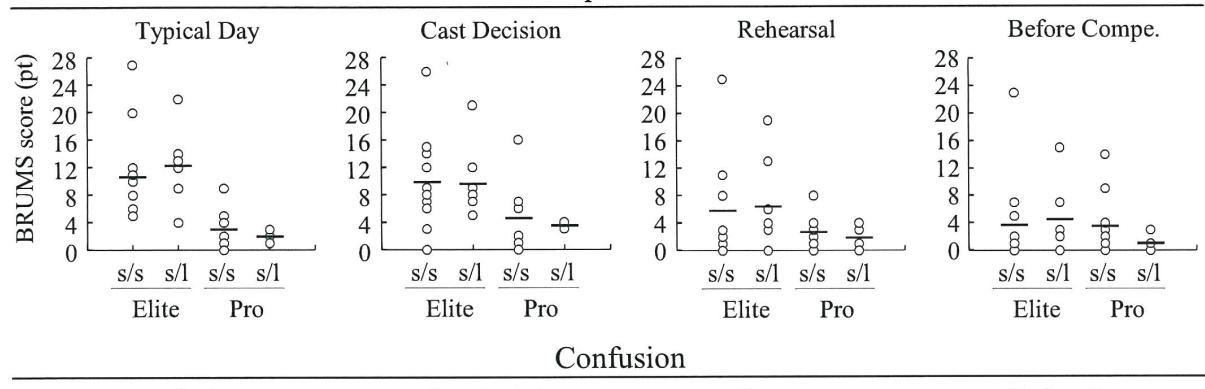

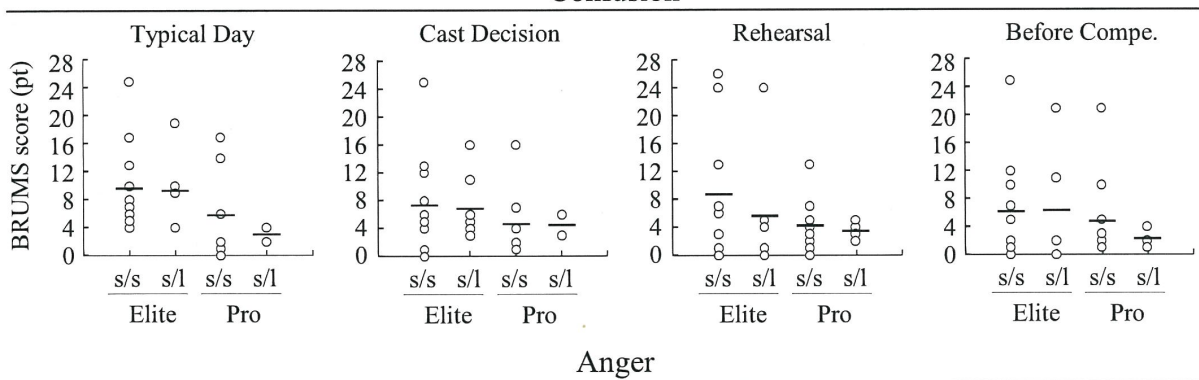

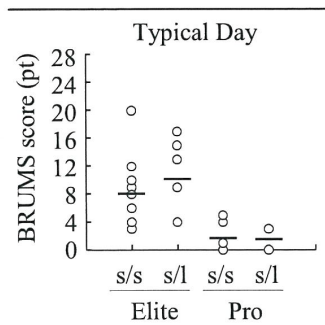
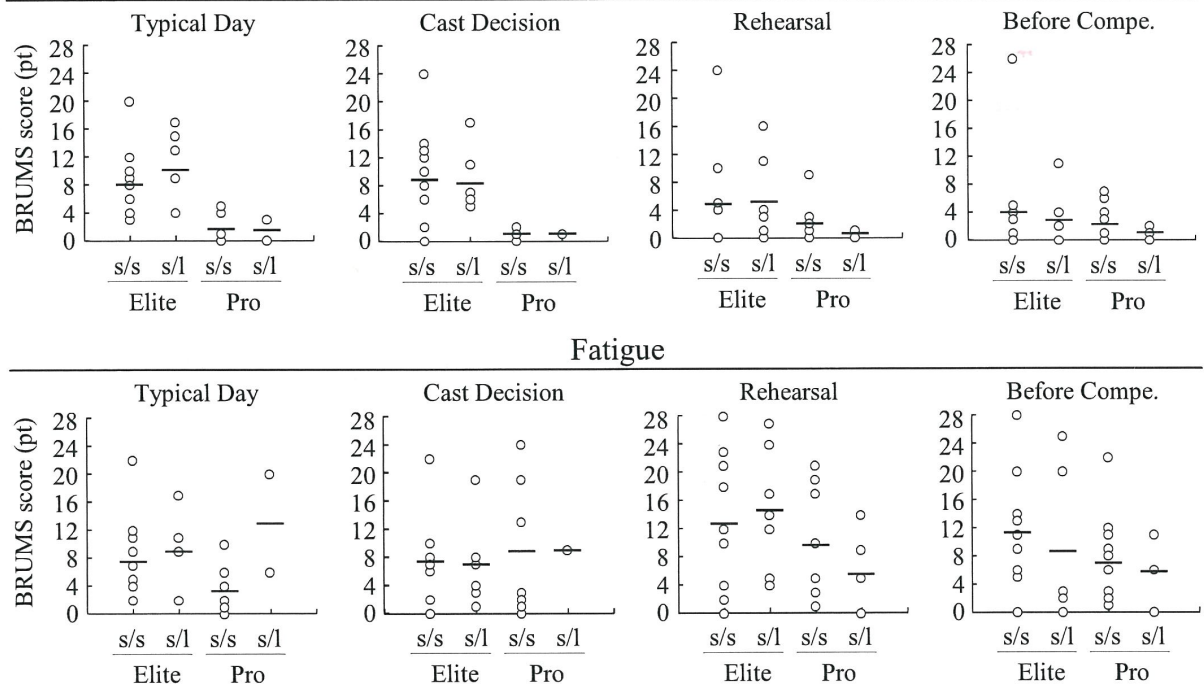

Figure 1. Relationship between BRUMS scores and 5-HTTLPR genotypes in Elite and Pro dancers. Bars represent average BRUMS scores for each group. Compe: Competition 
for Pro dancers on the cast decision day $(P<0.006)$. On the other hand, Depression and Anger levels gradually decreased for Elite dancers over time. Consequently, there was no significant difference in Depression or Anger between Elite and Pro dancers before the competition $(P=0.385 ; P=0.364$, respectively). In addition, Pro dancers who had the $\mathrm{s} / \mathrm{l}$ genotype tended to show lower Depression and Anger values on the four test days.

Confusion: There was no significant difference on any of the test days. Confusion scores tend to be higher for Elite than Pro dancers. As was the case for Depression and Anger, Confusion in the Pro dancers with the s/l genotype seemed to be low across the four test days.

Fatigue: Fatigue levels in dancers who had the s/s genotype were significantly lower than those of the s/l genotype dancers on the typical day, such that there was a main effect of 5-HTTLPR genotype $(P<0.042)$. In addition, Fatigue tended to be significantly lower in Pro than in Elite dancers on rehearsal day $(P=0.054)$.

Although Elite dancers showed higher BRUMS scores for Tension, Depression, and Anger on the typical day compared with Pro dancers, these differences generally seemed to decrease over time. This pattern suggests that Elite dancers experience more distress during routine practice. From the viewpoint of 5-HTTLPR genotype, there was a significant difference for the Fatigue scale only on the typical day $(P<0.042)$. There were no such differences in the Fatigue scale for the other days assessed. The 5-HTTLPR genotype appears to exert a relatively minor effect on emotional state, with no evidence for an influence on time-dependent changes.

\section{Representative data for time-dependent changes in various feelings}

To clarify how BRUMS scores changed over the course of the four test days for each participant, we further investigated time-dependent changes in various feelings at an individual level.

Four representative data sets are displayed in Figure 2. Elite No. 16, who has the s/s genotype, showed high Tension, Depression, Confusion, and Anger scale scores on the typical day (Figure 2a). Tension, Confusion, and Anger scores remained moderately elevated over the course of the four test days in this participant. Elite No. 33 in the s/l genotype group also exhibited high Tension, Depression, and Anger scores on the typical day, which decreased from the cast decision day (Figure 2b). On the other hand, Pro No. 4 in the s/s genotype group showed low Tension, Depression, and Anger scale scores over the four test days (Figure 2c). Pro No. 6 dancer, with the s/l genotype, had low Tension, Depression, and Anger scores across the four days, with moderate Fatigue scores (Figure 2d). These observations suggest that Pro dancers show no appreciable time-dependent changes in the various emotions, in contrast to Elite dancers.

\section{Relationships between Trait-Anxiety and BRUMS scores}

To investigate whether we can predict psychological condition before competition day using Trait-Anxiety scores instead of 5-HTTLPR gene types, we analyzed the relationships between TraitAnxiety on the typical day and BRUMS scores. Almost all of the BRUMS scores were significantly correlated with Trait-Anxiety scores in Elite dancers (Figure 3). These dancers showed high correlations between Trait-Anxiety scores and Tension, Depression, Confusion, Anger, and Fatigue scores. These observations suggest that the Trait-anxiety during practice might contribute to negative states on subsequent days before competition. In the Pro group, on the other hand, no significant a

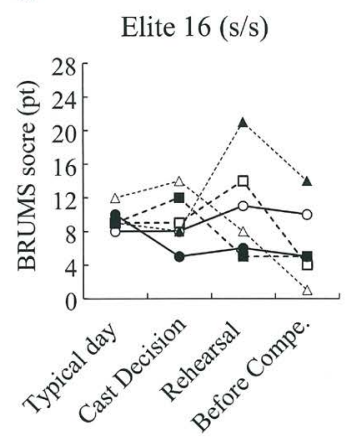

b

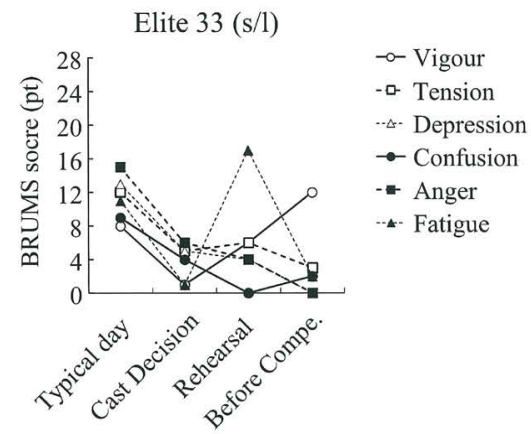

c

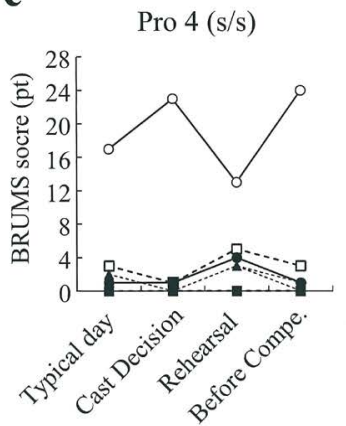

d

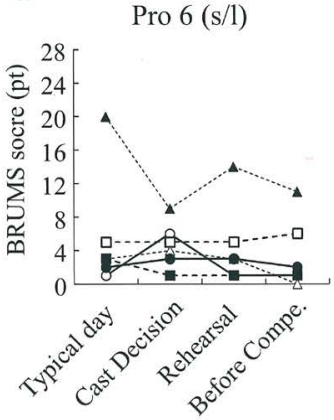

Figure 2. Individual data for BRUMS score time course. (a) Mood scales in Elite No. 16 (s/s). (b) Mood scales in Elite No. 33 (s/l). (c) Mood scales in Pro No. 4 (s/s). (d) Mood scales in Pro No. 6 (s/l). Compe: Competition

correlations between Trait-Anxiety scores and mood scales were observed, except for Depression scores on the rehearsal day $(r=0.543$, $P<0.05)$. There was no correlation between Trait-Anxiety scores and Fatigue scores. Because Pro dancers perform relatively calmly, their emotional shifts could not be detected by using a subjective evaluation. Therefore, our data suggest that it would be easier to predict the mood states of Elite dancers on the basis of Trait-anxiety, whereas this is not possible for Pro dancers, presumably due to the ability of the latter to practice in a more calm state.

\section{Discussion}

It is important to know what psychological states are experienced by dancers on both typical practice days and under more stressful conditions, as such states would be expected to influence performance. To explore the possibility that the 5-HTTLPR genotype could serve as an objective indicator for the prediction of mental states in ballet dancers, we investigated the relationship between the 5-HTTLPR genotype and various emotions in Japanese ballet dancers under stress conditions.

The frequencies of the 5-HTTLPR genotype in our samples were quite different from that observed in the Western population, which were $18.8 \%$ for the s/s genotype and $32.3 \%$ for the $1 / 1$ genotype in one previous study [5]. The frequencies observed in the present study were similar to those seen in the Korean population, which consists of $61.6 \%$ for the s/s genotype, $34.1 \%$ for the s/l genotype, and $4.3 \%$ for the $1 / 1$ genotype [14]. These observations suggest that Asian populations such as China and Korea showed an increased frequency of the s/s genotype relative to Western populations. 5-HTTLPR genotype did not significantly affect the Trait-Anxiety scores in our sample of dancers, although Elite dancers showed more Trait-anxiety than Pro 

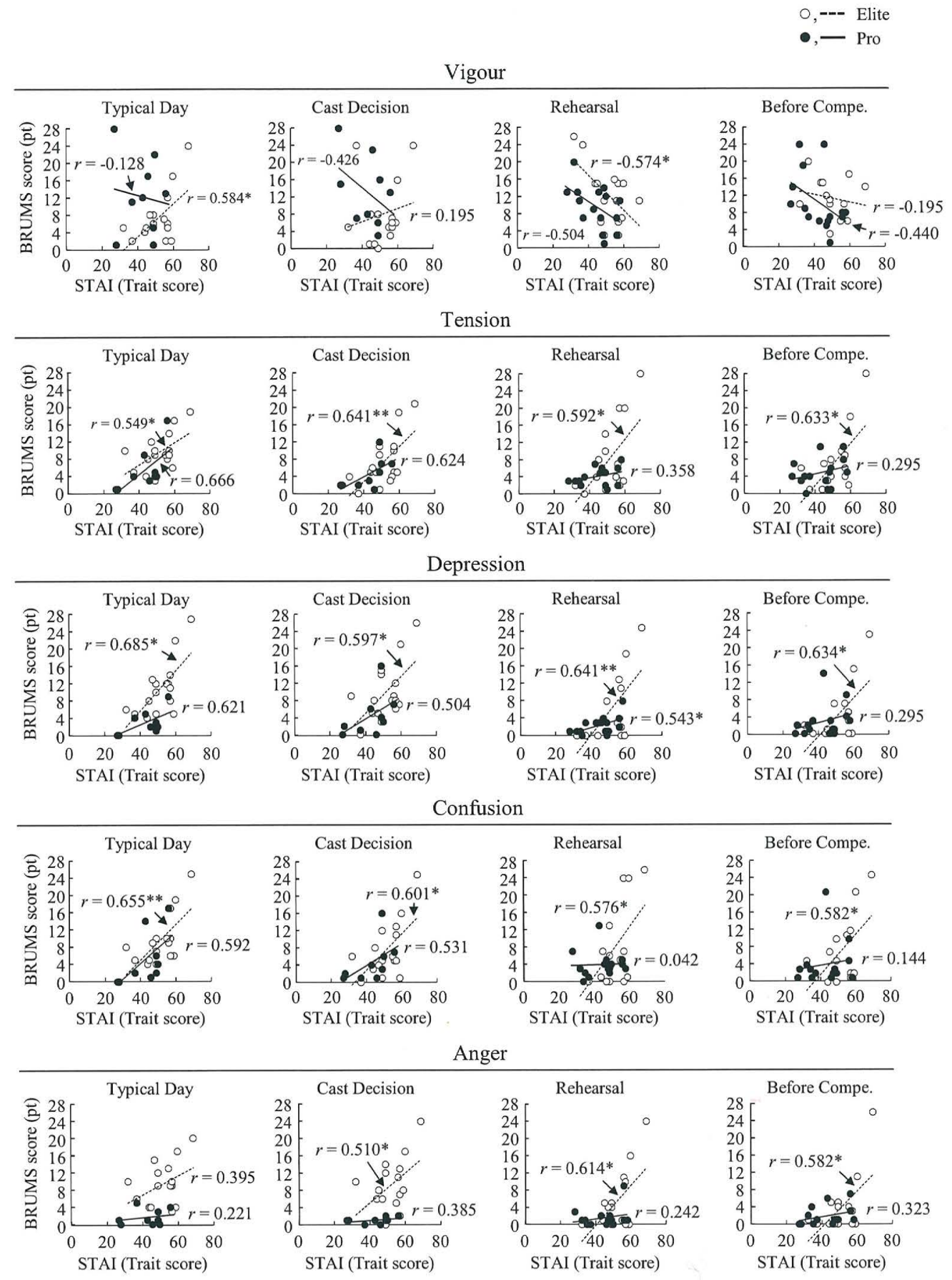

Fatigue

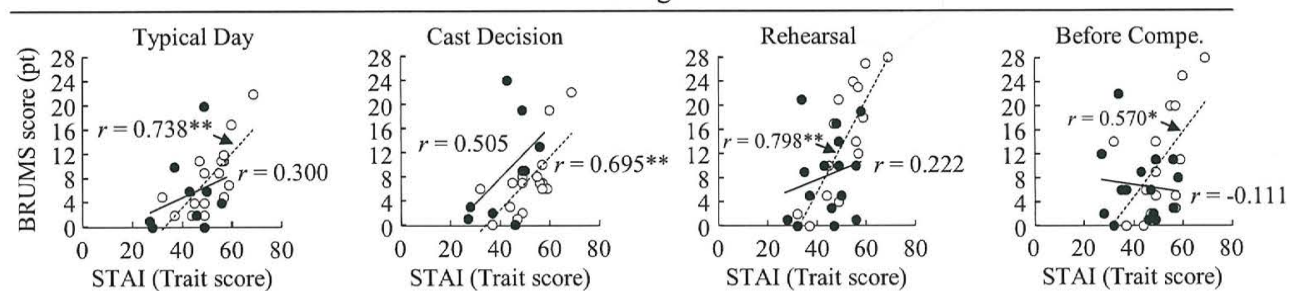

Figure 3. Correlations between Trait-Anxiety (STAI) scores on the typical day and BRUMS scores in Elite and Pro dancers. Open circle shows the scores of Elite dancers, and closed circle shows those of Pro dancers. Dotted line represents the regression line of the scores of Elite dancers, and solid line is that of Pro dancers. $r$, Pearson correlation coefficient. $* P<0.05$, $* * P<0.01$. Compe: Competition 
dancers. Since the Japanese female standard score for Trait-Anxiety is 40-49 points according to Form JYZ, the above results indicate that Trait-Anxiety scores in Elite dancers tended to be higher than those in the general Japanese population. However, the standard deviations of s/s genotype seem to be large, to be connected by individual stress conditions. In other words, the person with s/s genotype might tend to fluctuate their moods under stressful conditions (Figure 4). Since the State-Anxiety shows the presence of anxiety at the time of assessment, all dancers seemed to have the same levels of anxiety on the typical day in the population. These data are showing that the Trait-Anxiety scores would be affected by the factor of Elite/Pro, rather than the 5-HTTLPR genotype (see Table 3 ).

A previous study suggests that Japanese cultural factors seem to suppress the expression of positive feelings, such that it is particularly important to distinguish between two anxiety components in Japanese samples: subscales P and A [28]. Subscale P indicates that TraitAnxiety is present, such as the question "I feel blue". Subscale A represents the absence of anxiety, such as the question "I feel pleasant". We observed that subscale A scores were higher in Elite than in Pro dancers, perhaps indicative of less confidence. Elite dancers seem to have a sense of inferiority, and to underestimate themselves compared with Pro dancers.

BRUMS scores also exhibited different patterns in Elite and Pro dancers. Elite dancers showed high BRUMS scores for Tension, Depression, and Anger on the typical day compared with Pro dancers. In addition, these scores in Elite dancers changed in a timedependent manner, while Pro dancers were relative stable on BRUMS scores. 5-HTTLPR genotype significantly affected only Fatigue scale scores on the typical day, with no differences as a function for genotype for the other days assessed. 5-HTTLPR genotype may be used to indicate the score of hedonic scale principle of Fatigue scale generally. These observations suggest that profession status influences dancer psychological states, with 5-HTTLPR genotype providing comparatively little in the way of predictive value.

We also investigated the relationship between Trait-Anxiety scores on the typical day and BRUMS scores under stress conditions. Our data suggest that the Elite dancers who showed high Trait-Anxiety on the typical day tended to get nervous, depressed, confused, angry, and tired on the day before competition. Therefore, their ballet teachers/leaders and technical supporters would need to communicate frequently with the Elite dancers on the rehearsal day or the day before competition. In Pro dancers, on the other hand, there was almost no association between Trait-Anxiety and BRUMS scores. It seems to be hard to use the TraitAnxiety scores for the prediction of mental situation in Pro dancers.
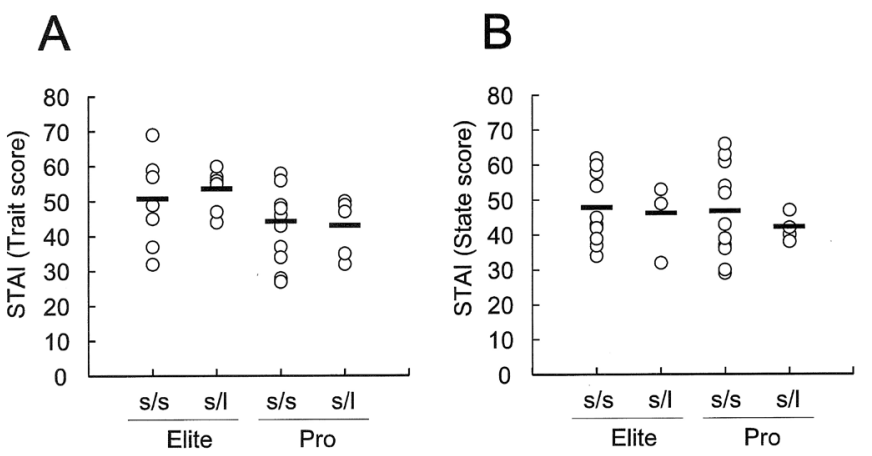

Figure 4. STAI on the typical day. (A) Trait-Anxiety, (B) State-Anxiety.
The different moods patterns observed here for Elite and Pro dancers may be the result of confidence in their performance. Dancers may develop the ability to control their emotions through everyday exercise and abundant experience on the way to becoming professionals. In addition, we observed that Pro dancers usually communicate with their colleagues, unlike Elite dancers, which would contribute to the relative stability of emotion observed for Pro dancers. These differences between Pro and Elite dancers can also be expected to affect frequency of injuries. In fact, most Elite dancers had minor or major injuries during the present study period, whereas Pro dancers rarely had major injuries (data not shown).

The 5-HTTLPR genotype affects the transcriptional level of the 5-HTT gene, with the $\mathrm{s}$ allele transcriptionally less efficient than the 1 allele [5]. The genotype is associated with anxiety-related temperamental traits and the reactivity of the amygdala, which contribute to vulnerability for affective disorders [8,32-34]. Previous studies reveal that these situations exhibit a significant difference between $\mathrm{s} / \mathrm{s}$ and $1 / 1$ genotypes, by divisions of $\mathrm{S}$-form possession (a dominant model: $\mathrm{s} / \mathrm{s}$ and $\mathrm{s} / \mathrm{l} \mathrm{vs} \mathrm{l} / \mathrm{l}$ ) and L-form possession (a recessive model: s/s vs s/l and l/l) [5,9,14,35-37]. Because we had no dancer with the $1 / 1$ genotype in this study, there remains a possibility that we could not detect a significant association of the 5-HTTLPR genotype with psychological states in our population. Further experiments are needed for more precise evaluation.

\section{Conclusions}

Our data suggests that we can predict the status of 6 scales of BRUMS before the competition by examining the Trait-Anxiety in Elite, while it may be rather difficult to predict the mental status of Pro before the competition. It was difficult to predict the mental situation of dancers before the competition by the date of 5-HTTLPR genotype only. However, the BRUMS scores were the main effects in 5-HTTLPR $(P<0.035)$ and in Pro/Elite $(P<0.002)$ groups through 4 conditions days. There were significant differences in 5-HTTLPR and Pro/Elite groups through all of 6 mood scales, and it was concerned with in the pattern of the feelings.

Professional status of dancers was a robust predictor of dancer emotional states, whereas 5-HTTLPR genotype showed little predictive value in Japanese population. We should be able to optimize predictive accuracy by combining Trait-Anxiety scores with data for other genotypes, such as noradrenalin or dopamine related gene polymorphisms.

\section{Acknowledgment}

This work was supported by a Grant-in-Aid for Scientific Research (C) (No.25350789) from Japan Society for the Promotion of Science (JSPS). We also wish to express our sincere appreciation to Mr. Masayuki Oda, $\mathrm{PhD}$, the late Research Associate, Department of Pharmacogenomics, St. Marianna University Graduate School of Medicine for the analysis of our data.

\section{Competing interest}

The authors declare that they have no competing interests.

\section{References}

1. Baumeister RF (1984) Choking under pressure: self-consciousness and paradoxical effects of incentives on skillful performance. J Pers Soc Psychol 46: 610-620. [Crossref]

2. Tanaka Y, Sekiya H (2010) The relationships between psychological/physiological 
changes and behavioral/performance changes of a golf putting task under pressure. Int J Sport Health Sci 8: 83-94.

3. Coelho RW, Kuczynski KM, Juliana M, Paes DDLG, Santos PB, et al. (2014) Effect of a mental training program on salivary cortisol in volleyball players. J Exercise Physiol 17: 46-57.

4. MacDonald DJ, McIsaac T, Beck JL (2015) Coach perceptions of the impact of a mental training program in preparing Special Olympics athletes for competition. Movement, and Sport 47

5. Lesch KP, Bengel D, Heils A, Sabol SZ, Greenberg BD, et al. (1996) Association of anxiety-related traits with a polymorphism in the serotonin transporter gene regulatory region. Science 274: 1527-1531. [Crossref]

6. Hariri AR, Mattay VS, Tessitore A, Kolachana B, Fera F, et al. (2002) Serotonin transporter genetic variation and the response of the human amygdala. Science 297: 400-403. [Crossref]

7. Hariri AR, Holmes A (2006) Genetics of emotional regulation: the role of the serotonin transporter in neural function. Trends Cogn Sci 10: 182-191. [Crossref]

8. Kalin NH, Shelton SE, Fox AS, Rogers J, Oakes TR, et al. (2008) The serotonin transporter genotype is associated with intermediate brain phenotypes that depend on the context of eliciting stressor. Mol Psychiatry 13: 1021-1027. [Crossref]

9. Melke J, Landén M, Baghei F, Rosmond R, Holm G, et al. (2001) Serotonin transporter gene polymorphisms are associated with anxiety-related personality traits in women. Am J Med Genet 105: 458-463. [Crossref]

10. Blom RM, Samuels J F, Riddle MA, Bienvenu OJ, Grados MA, et al. (2011) Association between a serotonin transporter promoter polymorphism (5HTTLPR) and personality disorder traits in a community sample. J Psychiatr Res 45: 1153-1159. [Crossref]

11. Ishii T, Wakabayashi R, Kurosaki H, Gemma A, Kida K (2011) Association of serotonin transporter gene variation with smoking, chronic obstructive pulmonary disease, and its depressive symptoms. J Hum Genet 56: 41-46. [Crossref]

12. Katsuragi S, Kunugi H, Sano A, Tsutsumi T, Isogawa K, et al. (1999) Association between serotonin transporter gene polymorphism and anxiety-related traits. Biol Psychiatry 45: 368-370. [Crossref]

13. Murakami F, Shimomura T, Kotani K, Ikawa S, Nanba E, et al. (1999) Anxiety traits associated with a polymorphism in the serotonin transporter gene regulatory region in the Japanese. J Hum Genet 44: 15-17. [Crossref]

14. Kim SJ, Kim YS, Choi NK, Hong HJ, Lee HS, et al. (2005) Serotonin transporter gene polymorphism and personality traits in a Korean population. Neuropsychobiology 51 : 243-247. [Crossref]

15. Mizuno T, Aoki M, Shimada Y, Inoue M, Nakaya K, et al. (2006) Gender difference in association between polymorphism of serotonin transporter gene regulatory region and anxiety. J Psychosom Res 60: 91-97. [Crossref]

16. Chua P, Krams M, Toni I, Passingham R, Dolan R (1999) A functional anatomy of anticipatory anxiety. Neuroimage 9: 563-571. [Crossref]

17. Flory JD, Manuck SB, Ferrell RE, Dent KM, Peters DG, et al. (1999) Neuroticism is not associated with the serotonin transporter (5-HTTLPR) polymorphism. Mol Psychiatry 4: 93-96. [Crossref]

18. Lang UE, Bajbouj M, Wernicke C, Rommelspacher H, Danker-Hopfe H, et al. (2004) No association of a functional polymorphism in the serotonin transporter gene promoter and anxiety-related personality traits. Neuropsychobiology 49: 182-184. [Crossref]

19. Umekage T, Tochigi M, Marui T, Kato C, Hibino H, et al. (2003) Serotonin transporterlinked promoter region polymorphism and personality traits in a Japanese population. Neurosci lett 337: 13-16. [Crossref]

20. Bachner-Melman R, Dina C, Zohar AH, Constantini N, Lerer E, et al. (2005) AVPR1a and SLC6A4 gene polymorphisms are associated with creative dance performance PLoS Genet 1: e42. [Crossref]

21. Steptoe A, Fidler H (1987) Stage fright in orchestral musicians: A study of cognitive and behavioural strategies in performance anxiety. Br J Psychol 78: 241-249. [Crossref]

22. Marchant-Haycox SE, Wilson GD (1992) Personality and stress in performing artists Personality and Individual Differences 13: 1061-1068.

23. Tamborrino RA (2001) An examination of performance anxiety associated with solo performance of college-level music majors (Doctoral dissertation, ProQuest Information \& Learning).

24. Kenny DT, Davis P, Oates J (2004) Music performance anxiety and occupational stress amongst opera chorus artists and their relationship with state and trait anxiety and perfectionism. J Anxiety Disord 18: 757-777. [Crossref]

25. Yatabe K, Yui N, Kasuya S, Fujiya H, Tateishi K, et al. (2014) Anxiety and Mood among Ballet Dancers: A Pilot Study on Effects of a Medical Approach Involving Periodic Intervention. Annals Sports Med Res 1: E1002.

26. Yatabe K, Kumai T, Fujiya H, Yui N, Tateishi K, et al. (2014) Association of JapaneseSpecific Anxiety-Related Traits With a Polymorphism in the Serotonin Transporter Gene Under Pressure in Ballet Dancers. XXXIII FIMS World Congress of Sports Medicine and Canadian Academy of Sport and Exercise Medicine, From Prevention to Performance, June 18-21, 2014, Quebec City, Quebec, Canada. Clin J Sport Med 24.

27. Langley JM, Halperin SA, Smith B (2003) A pilot study to quantify parental anxiety associated with enrollment of an infant or toddler in a phase III vaccine trial. Vaccine 21: 3863-3866. [Crossref]

28. Hidano N, Fukuhara M, Iwawaki M, Soga S, Spielberger CD (2000) State-trait anxiety inventory-form JYZ. Tokyo: Japan UNI Agency (in Japanese).

29. Terry PC, Lane AM (2003) User guide for the Brunel mood scale (BRUMS). University of Southern Queensland, Australia, Toowoomba and University of Wolverhampton, Wolverhampton, UK.

30. Yatabe K, Oyama T, Fujiya H, Kato H, Seki H , et al. (2006) Development and Validation of the Preliminary Japanese Version of the Profile of Mood States for Adolescent POMS-A. The St. Marianna Med J 34: 539-547.

31. Yatabe K, Oyama T (2007) The Profile of Mood States for Adolescents (POMS-A) Nihongoban no sakusei -dai 2 ho- [Reliability and validity of the Profile of Mood State for Adolescent (POMS-A): The second report]. Nihon Shinri Gakkai Taikai Happyo Ronbunshu [Japanese Psychological Association Proceedings], 71: 947.

32. Jabbi M, Korf J, Kema IP, Hartman C, Van der Pompe G, et al. (2007) Convergent genetic modulation of the endocrine stress response involves polymorphic variations of 5-HTT, COMT and MAOA. Mol Psychiatry 12: 483-490. [Crossref]

33. Mikheenko Y, Shiba Y, Sawiak S, Braesicke K, Cockcroft G, et al. (2015) Serotonergic, brain volume and attentional correlates of trait anxiety in primates. Neuropsychopharmacology 40: 1395-1404. [Crossref]

34. Shiba Y, Santangelo AM, Braesicke KC, Agustín-Pavón C, Cockcroft G, et al. (2014) Individual differences in behavioral and cardiovascular reactivity to emotive stimuli and their relationship to cognitive flexibility in a primate model of trait anxiety. Front Behav Neurosci 8: 137. [Crossref]

35. Greenberg BD, Li Q, Lucas FR, Hu S, Sirota, LA, et al. (2000) Association between the serotonin transporter promoter polymorphism and personality traits in a primarily female population sample. Am J Med Genet 96: 202-216. [Crossref]

36. Risch N, Herrell R, Lehner T, Liang KY, Eaves L, et al. (2009) Interaction between the serotonin transporter gene (5-HTTLPR), stressful life events, and risk of depression: a meta-analysis. JAMA 301: 2462-2471. [Crossref]

37. Williams LM, Gatt JM, Schofield PR, Olivieri G, Peduto A, et al. (2009) 'Negativity bias' in risk for depression and anxiety: brain-body fear circuitry correlates, 5-HTTLPR and early life stress. Neuroimage 47: 804-814. [Crossref]

Copyright: (C2016 Yatabe K. This is an open-access article distributed under the terms of the Creative Commons Attribution License, which permits unrestricted use, distribution, and reproduction in any medium, provided the original author and source are credited. 